\title{
Alginate/Carboxymethyl Cellulose Hydrogel Films in Relation to Crosslinking with Glutaraldehyde and Copper Sulfate
}

\author{
Watcharee Sritweesinsub ${ }^{1}$, Sireerat Charuchinda ${ }^{2, a}$ \\ ${ }^{1}$ Interdisciplinary Program in Petrochemistry \& Polymer Science, Faculty of Science, Chulalongkorn University, \\ Bangkok 10330 THAILAND \\ ${ }^{2}$ Department of Materials Science, Faculty of Science, Chulalongkorn University, Bangkok 10330 THAILAND
}

\begin{abstract}
Alginate/carboxymethyl cellulose (CMC) hydrogel films using glutaraldehyde (GA) and/or copper sulfate $\left(\mathrm{Cu}^{2+}\right)$ as crosslinking agents were prepared. The ratios of alginate to $\mathrm{CMC}$ were varied at $0: 10,2: 8,4: 6,6: 4,8: 2$ and 10:0 in the presence of GA at $0,2,5 \%$ and/or copper sulfate of 0 and $0.02 \mathrm{~mol}$. The Fourier Transform Infrared Spectroscopy (FTIR) spectra of hydrogels indicated the intermolecular interaction between CMC with GA and alginate with $\mathrm{Cu}^{2+}$. Using a couple of $\mathrm{GA}$ and $\mathrm{Cu}^{2+}$, as crosslinking agents, the hydrogels exhibited better swelling time than that of a crosslinking agent alone. The percentages of solid remains were increased by increasing both of alginate ratio and $\mathrm{Cu}^{2+}$ content.
\end{abstract}

\section{Introduction}

Hydrogels based on natural polysaccharide such as cellulose and its derivatives, chitosan, starch, alginate and dextrin are widely utilized in medical applications such as drug delivery, contact lens because of their high biocompatibility, biodegradability and non-toxicity [1]. However, these hydrogels have limited mechanical properties and water retention [2]. These can be improved by preparation of three-dimensional networks structure of hydrogels via physical, chemical and ionic crosslinking [3]. Alginate, a linear polysaccharide (1-4) linked a Lguluronic and $\beta$ - D-mannuronic acid extracted from brown seaweed, can be ionic cross-linked by divalent or trivalent ions of both guluronic acid and mannuronic acid groups in the side chain leading to water-insoluble [4] Carboxymethyl cellulose (CMC), a hydrophilic anionic polymer derived from cellulose, enable water binding and moisture sorption properties due to its many hydroxyl and carboxylic groups. It can be chemical cross-linked using bifunctional crosslinking agent such as epichrolohydrin, formaldehyde and can be then swelled to form hydrogels and absorbs large amount of water $[5,6]$.

In this study, alginate/carboxymethyl cellulose hydrogel films cross-linked with glutaraldehyde (GA) and copper sulfate $\left(\mathrm{Cu}^{2+}\right)$ were prepared. The structure of the hydrogel film was characterized by Fourier transform infrared spectroscopy. The swelling behavior of the hydrogels under different concentration of alginate and $\mathrm{CMC}$ with different types and amounts of crosslinking agents were also investigated.

\section{Experimental}

\subsection{Materials}

Soduim alginate (Alg) and CMC were kindly supplied by August Chem Co., Ltd. (Bangkok, Thailand). Glutaraldehyde (GA) $25 \%$ w/v (AR grade) and copper sulfate $\left(\mathrm{CuSO}_{4} \cdot 5 \mathrm{H}_{2} \mathrm{O}\right)\left(\mathrm{Cu}^{2+}\right)$ used as crosslinking agents were purchased from Sigma-Aldrich and Altima Chemical, respectively.

\subsection{Preparation of Aginate/CMC hydrogel films}

Dissolve $2 \mathrm{~g}$ of polymer powder in various ratios of $\mathrm{Alg}$ to $\mathrm{CMC}(0: 10,2: 8,4: 6,6: 4,8: 2$ and 10:0) into $100 \mathrm{ml}$ distilled water by continuous magnetic stirring at $60{ }^{\circ} \mathrm{C}$ for $24 \mathrm{~h}$. The obtained mixtures were cross-linked by addition of GA $(25 \% \mathrm{w} / \mathrm{v})$ at $0,2,5 \%$ and/or copper sulfate of 0 and $0.02 \mathrm{~mol}$ as shown in Table 1 . The mixture was then continuously stirred for $30 \mathrm{~min}$. The homogeneous mixtures were casted into the petri dishes. The hydrogel films were allowed to set at $40{ }^{\circ} \mathrm{C}$ until completely dried.

\subsection{Characterization.}

Chemical structure and the presence of specific chemical groups of materials were characterized by ATR-FTIR (Nicolet 6700, Thermo Electron Corporation) using Transmittance Mode. FTIR spectra were obtained in the

\footnotetext{
$\overline{{ }^{a} \text { Corresponding author: sireerat.c@ }}$ chula.ac.th
} 
range of wavenumber from 4000 to $400 \mathrm{~cm}^{-1}$ during 64 scans, with $2 \mathrm{~cm}^{-1}$ resolution.

Table 1. Composition of the formulated Alginate/CMC hydrogels.

\begin{tabular}{llll}
\hline Sample Code & $\begin{array}{l}\text { Alg:CMC } \\
{[\% \mathbf{w} / \mathbf{w}]}\end{array}$ & $\begin{array}{l}\mathbf{G A} \\
{[\mathbf{w t} \%]}\end{array}$ & $\begin{array}{l}\mathbf{C u}^{2+} \\
{[\mathbf{m o l}]}\end{array}$ \\
\hline Alginate & $2: 0$ & & \\
CMC & $0: 2$ & 0 & 0 \\
\hline A2C8-G5 & $0.4: 1.6$ & & \\
A4C6-G5 & $0.8: 1.2$ & & \\
A6C4-G5 & $1.2: 0.8$ & 5 & 0 \\
A8C2-G5 & $1.6: 0.4$ & & \\
\hline A2C8-Cu2 & $0.4: 1.6$ & & \\
A4C6-Cu2 & $0.8: 1.2$ & & \\
A6C4-Cu2 & $1.2: 0.8$ & 0 & \\
A8C2-Cu2 & $1.6: 0.4$ & & \\
\hline A2C8-G2Cu2 & $0.4: 1.6$ & & \\
A4C6-G2Cu2 & $0.8: 1.2$ & & \\
A6C4-G2Cu2 & $1.2: 0.8$ & 2 & \\
A8C2-G2Cu2 & $1.6: 0.4$ & & \\
A10C0-G2Cu2 & $2.0: 0$ & & \\
\hline A2C8-G5Cu2 & $0.4: 1.6$ & & \\
A4C6-G5Cu2 & $0.8: 1.2$ & & \\
A6C4-G5Cu2 & $1.2: 0.8$ & 5 & \\
A8C2-G5Cu2 & $1.6: 0.4$ & & \\
A10C0-G5Cu2 & $2.0: 0$ & & \\
\hline
\end{tabular}

\subsection{Swelling behavior}

The swelling ratios of hydrogel films were determined at various times. The samples were immersed in distilled water and then removed at different time breaks, wipe with tissue paper, weighed and quickly returned to distilled water. The swelling studies were performed in triplicate. The swelling ratio was then calculated using the following equation:

$$
\text { Swelling ratio }=(W s-W d / W d) \times 100
$$

where $W s$ and $W d$ are the weight of the films in swollen and dry state, respectively.

\subsection{Percentages of solid remain}

To determine the percentage of solid, crosslinked samples $\left(2 \times 2 \mathrm{~cm}^{2}\right)$ of alginate/CMC hydrogel films were previously dried and then immersed in $50 \mathrm{ml}$ of distilled water at $25{ }^{\circ} \mathrm{C}$ for $24 \mathrm{~h}$. Afterwards, the samples were removed from the medium and were then dried in an oven at $60{ }^{\circ} \mathrm{C}$. The percentages of solid remain were determined by the following equation:

$$
\text { Percentages of solid remain }=(W i-W f / W i) \times 100
$$

where Wi represents the initial dry weight of the film before immersion in distilled water, and Wf corresponds to the dry weight of the film after immersion. The percentage of solid remain were performed in triplicate.

\section{Results and discussion}

\subsection{Characterization of FTIR}

The FTIR spectra of CMC cross-linked with GA and alginate cross-linked with $\mathrm{Cu}^{2+}$ were compared with pure alginate and pure CMC in Figure. 1. All major peaks of pure alginate showed at 3450 and $2890 \mathrm{~cm}^{-1}, 1600$ and $1425 \mathrm{~cm}^{-1}$ and $1040 \mathrm{~cm}^{-1}$ which have been assigned to the $\mathrm{O}-\mathrm{H}$ stretching and $-\mathrm{CH}$ stretching, the asymmetric and symmetric vibration of $-\mathrm{COO}$ stretching and $\mathrm{C}-\mathrm{O}-\mathrm{C}$ stretching, respectively. CMC were observed characteristic absorption peaks at 3450 and $2890 \mathrm{~cm}^{-1}$, 1620 and $1420 \mathrm{~cm}^{-1}$ and $1323 \mathrm{~cm}^{-1}$ which have been assigned to vibration of $\mathrm{O}-\mathrm{H}$ and $-\mathrm{CH}$ stretching and the asymmetrical and symmetrical vibrations of carboxyl group the in $\mathrm{CMC}$ and $\mathrm{C}-\mathrm{O}$ stretching vibrations, respectively. The cross-linked hydrogel films with GA showed the duplet absorption peak near $2869 \mathrm{~cm}^{-1}$ corresponding to the $\mathrm{C}-\mathrm{H}$ stretching of the aldehyde group. Furthermore, strong band of carbonyl group $(\mathrm{C}=\mathrm{O}$ at $1580-1600 \mathrm{~cm}^{-1}$ ) was verified. The $\mathrm{O}-\mathrm{H}$ stretching vibration peak $\left(3600-3200 \mathrm{~cm}^{-1}\right)$ was relatively decreased when compared to pure CMC. The band of cross-linked hydrogel films with $\mathrm{Cu}^{2+}$ showed characteristic absorption bands shift at $1590 \mathrm{~cm}^{-1}$ and $1420 \mathrm{~cm}^{-1}$ which were attributed to the asymmetrical and symmetrical vibrations of $-\mathrm{COO}$ stretching in alginate. The FTIR results showed the interaction between carboxylate group of alginate and $\mathrm{Cu}^{2+}$ ion.

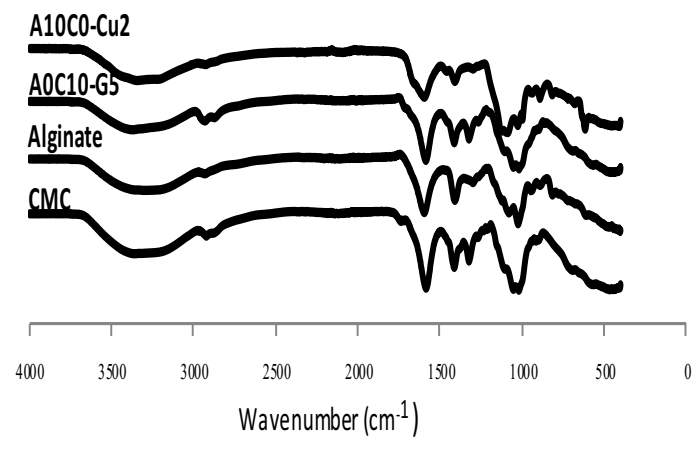

Figure. 1 FTIR spectra of hydrogel films.

\subsection{Swelling behavior}

Swelling behavior of cross-linked hydrogels films were shown in Figure. 2. The cross-linked films with GA alone (Figure. 2a) showed that an extremely increase in CMC to alginate ratio contributes to an improvement of the swelling ratio. It was suggested that glutaraldehyde could effectively crosslink at hydroxyl groups of CMC. The swelling ratio of cross-linked films with $\mathrm{Cu}^{2+}$ alone (Figure. 2b) could be slightly improved when the amount of alginate increased due to the crosslink interaction between $\mathrm{Cu}^{2+}$ and carboxylate group in alginate.

However, when a couple of crosslinking agents (GA and $\mathrm{Cu}_{2} \mathrm{SO}_{4}$ ) were employed (Figure. 2c), it showed the greater on swelling time than that of crosslinking agent alone ( 40 times). They could prolong time to reach 
maximum swelling value due to the formation of crosslinks between copper ion and carboxylate groups in alginate similar to the formation of cross-links between hydroxyl group of CMC and GA. The results indicated that an increase in alginate ratio lead to a decrease in swelling ratio because an enhancement of crosslink density caused water hardly interpenetrated to hydrogel structure [7].
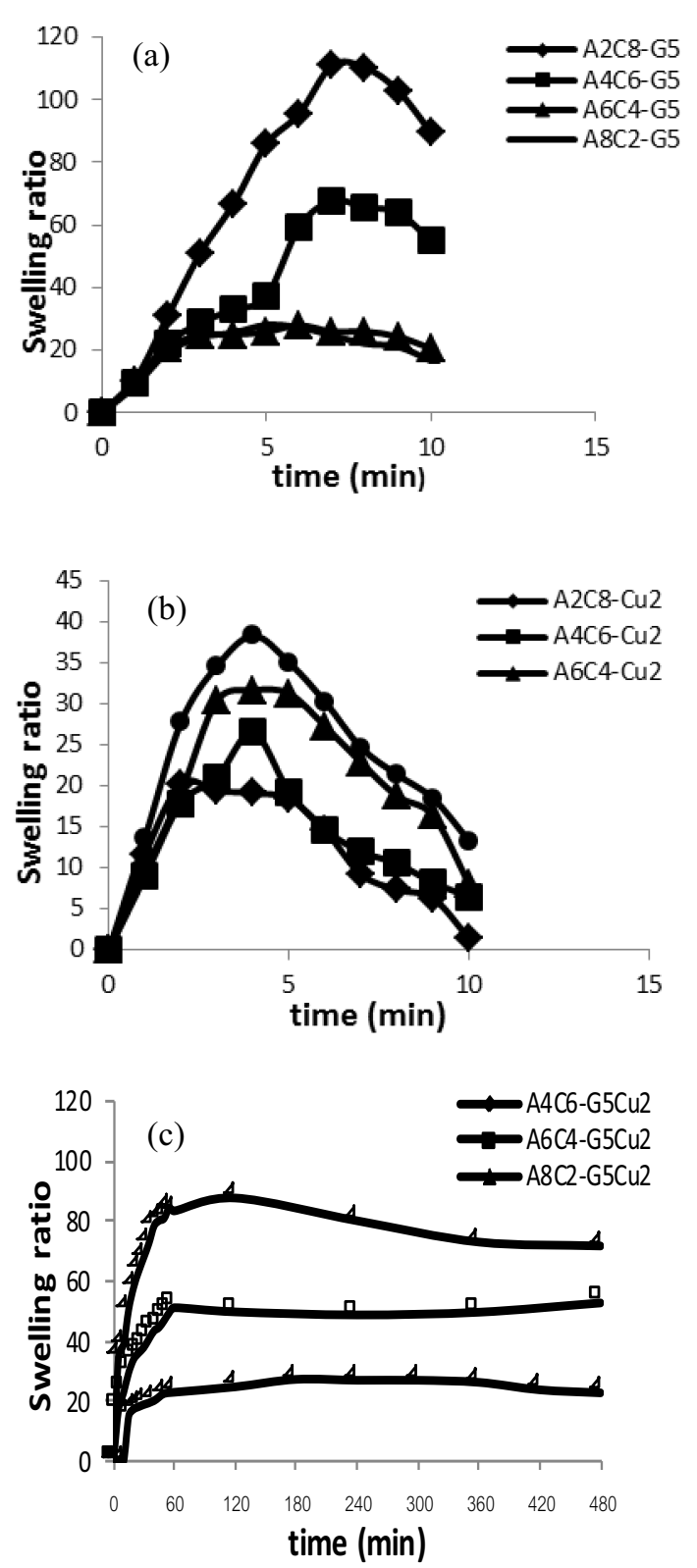

Figure. 2 Swelling rotio of alginate/CMC films cross-linked by (a) glutaraldehyde $5 \%$, (b) $\mathrm{Cu}_{2} \mathrm{SO}_{4} 0.2 \mathrm{~mol}$ (c) glutaraldehyde $5 \%$ and $\mathrm{Cu}_{2} \mathrm{SO}_{4} 0.02 \mathrm{~mol}$.

\subsection{Percentages of solid remain}

The percentages of solid remain of hydrogel films were investigated to determine their potential to be used in applications requiring a permanent contact with water. As shown in Figure. 3, the percentages of solid remain of the selected films cross-linked with a couple of crosslinking agents were evaluated. The increase in glutaraldehyde concentration increased the percentages of solid remains because of the formation of crosslinks between glutaraldehyde and hydroxyl group in CMC and alginate portion. In addition, the increase in the alginate proportion caused an increase in the percentages of solid remains. This may be due to the duration of alginate in water rather longer than $\mathrm{CMC}$ and the formation of crosslink between $\mathrm{Cu}^{2+}$ and carboxylate group occurring only in alginate portion [8].

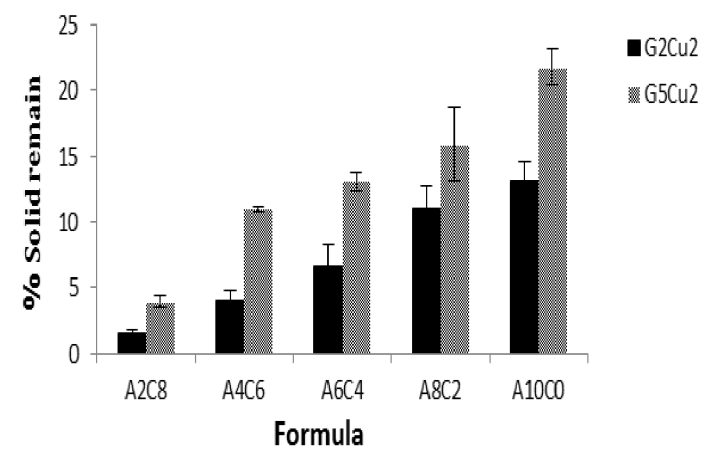

Figure. 3 Percentages of solid remain in water of cross-linked alginate/CMC hydrogel films.

\section{Summary}

The hydrogel films of alginate/CMC were successfully prepared by crosslinking with glutaraldehyde (GA) and copper sulfate $\left(\mathrm{Cu}^{2+}\right)$. FTIR spectra of alginate/CMC hydrogel have been confirmed an intermolecular interaction (H-bond) between $\mathrm{O}-\mathrm{H}$ group of $\mathrm{CMC}$ and GA and between carboxylic group of alginate and $\mathrm{Cu}^{2+}$ (ionic bond) leading to three-dimensional networks. The swelling property exhibited higher swelling time when a couple of $\mathrm{GA}$ and $\mathrm{Cu}^{2+}$ were used. The percentages of solid remain (water dissolubility of films) increased with the increase in $\mathrm{Cu}^{2+}$ concentration and also alginate proportion. The maximum value of percentages of solid remain was found when hydrogels were prepared from alginate and $\mathrm{CMC}$ at the ratio of 10:0 with a couple of crosslonking agents $\left(\mathrm{GA}\right.$ and $\left.\mathrm{Cu}^{2+}\right)$. This may be due to the duration of alginate in water rather longer than $\mathrm{CMC}$ and the formation of crosslink between $\mathrm{Cu}^{2+}$ and carboxylate group occurring only in alginate portion.

\section{Acknowledgements}

This research has been supported by the Ratchadaphiseksomphot Endowment Fund 2013 of Chulalongkorn University (CU-56-416-AM).

\section{References}

1. J. Yu, G. Yang, Y. Li, J. Gao, Q. Lu, W. Yang, Polym eng Science. 84, 2312 (2014)

2. S. Banerjee, S. Singh, S. Bhattacharya, Inter Journal Biol Macromol. 57, 297 (2013)

3. H. Mansur, C. Sadahira, A. Souza, A. Mansur, mater.science.eng. 28, 539 (2008)

4. N. Chiaoprakobkij, N. Sanchavanakit, K. Subbalekha, K. Pavasant, Carbohyr Polym. 85, 548 (2011) 
5. H. Kono. Carbohyr Polym. 66, 84 (2014)

6. R. Barbucci, A. Magnani, M. Consumi, Macromol. 33, 7475 (2000)

7. C. Chang, B. Duan, L. Zhang. Polym. 50, 5470 (2009)
8. R. Pereira, A. Carvalho, D. C. Vaz, M.H. Gil, A. Mendes, P. Bartolo, Inter Journal of Bio Macro. 52 226 (2013) 